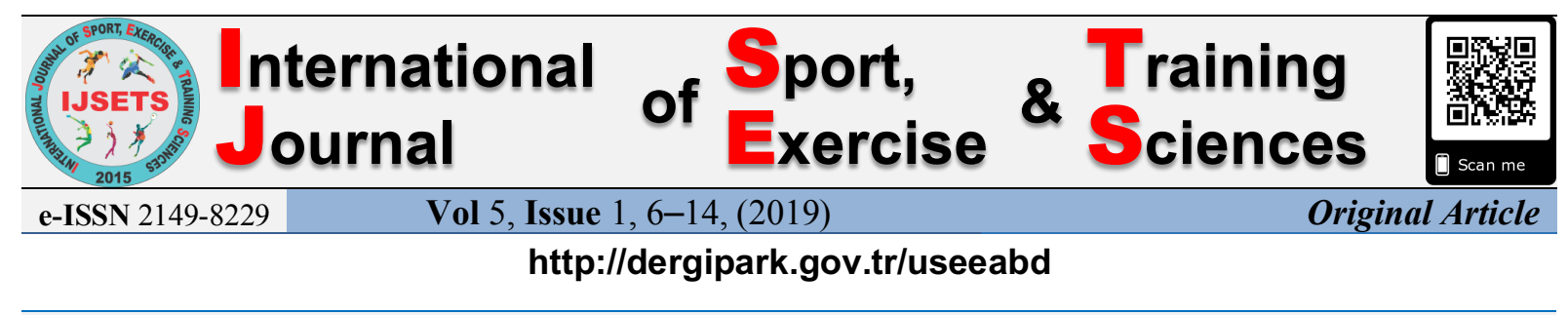

\title{
Effects of Scuba Diving Program on Bosnian War Veterans with Amputations
}

\author{
Zlatan Aganović ${ }^{1}$,
}

\begin{abstract}
Aim: Diving is an ideal sport for almost all people with physical disabilities, and therefore, has been increasingly popular as a way of rehabilitation for such people. The aim of this study was to determine the attainment of the elements of diving techniques, and the effects of programmed instruction of diving on the psychosocial status of war veterans with amputations.

Materials and Methods: The study was conducted on a sample of 12 male participants. In order to assess the psychosocial status of the applied sample, five different psychological scales were implemented before and after the diving training. Data analysis was performed using parametric and nonparametric statistics.

Results: After the three-week diving program, results show that the distribution of data has changed and is in favor of the final measurement. There is a statistically significant difference between initial and final measurements given that the $Z=-3.06$ index is significant at the level of $(p<0.01)$ adopted the elements of diving technique.

The results indicate that in patients with amputations, there has been an improvement in the Perception of Social Support.

Conclusion: The study showed that after a three-week programmed diving training, the quality of life of people with disabilities has improved and they adopted elements of diving techniques. This shows that people with disabilities are as well qualified for recreational diving when accompanied by a diving instructor, which again suggests that disability in and under water does not represent a barrier for recreational underwater activities.
\end{abstract}

Keywords

Disability,

Psychosocial,

Amputation, Veterans,

\section{INTRODUCTION}

The modern world of the $21^{\text {st }}$ century is becoming increasingly interested in the problem of people with disabilities. Causes of disability are diverse such as congenital anomalies, chronic illnesses, trauma, malnutrition etc. However, in considering disability causes, it is impossible to disregard armed conflicts and wars(Laferrier, Teodorski \& Cooper, 2015). Unfortunately, the territory of Bosnia and Herzegovina has been affected by war during which, due to explosive devices, there has been an increased number of disabled people, especially those with higher percentages of traumatic amputations in the total of amputees.

Cantor (1972) claims that the main indication of amputation is the preservation of life, i.e., the sacrifice of the body in order to preserve a whole. Disability arising as a result of amputation is a complex phenomenon. Starting from the fact that man represents one psychophysical entity, the integrity of the physical, psychological and social aspects of personality, that is, any type of integrity violation in any form, will lead to corresponding changes and consequences of the whole personality (Laferrier et al., 2015). Amputation causes a tremendous loss in terms of perception and body image. Shontz (1974) suggests that the person missing a limb has three images of the body. The first image of the body refers to the pre-amputated intact body, the second one on a body with a lack of limbs and the third one when the person is wearing prosthesis. Seymour (2002) states that regardless of the cause, amputation leads to significant and drastic changes in an individual's life, ranging from the state of shock to acceptance and finally to adjustment. Dramatic changes arising as a result of amputation are evident in the loss of function, sensation and body image, and, according to Gallagher and MacLachlan (2004), they affect the individual's quality of life in terms of limiting physical activity and leave long-term consequences in various segments of life quality.

Furthermore, Zidarov, Swaine, \& Gauthier-Gagnon (2009) found that lower-extremity amputations may affect the quality of life of amputees. Guttmann (1976) developed the introduction of sports as part of therapeutic programs in the rehabilitation of people with spinal cord injury. Since then, as Levy,

The role and contributions of each authors as in the section of IJSETS Writing Rules "Criteria for Authorship" is reported that: 1. Author: Contributions to the conception or design of the paper, data collection, writing of the paper and final approval of the version to be published paper, preparation of the paper according to rules of the journal, Statistical analysis, interpretation of the data.

${ }^{1}$ Corresponding Author: Sports Science Program, Qatar University, 2713, Doha/Qatar zlatan.aganovic@qu.edu.qa ORCID ID: 0000-0002-6490-8224 
Polman, Clough, Marchant and Earle (2006) state, there has been a dramatic increase of interest for sport activities among people with physical and intellectual disabilities. In addition, authors Buning and Schmeler (1999); Compton, Eisenman and Henderson (1989); Guttmann (1976); Noreau and Shepard (1995) indicate the usefulness of exercise and sport participation in man's physical and mental health, social functioning, as well as the overall quality of life. People with amputations have the necessity to pursue continuous and adequate physical activity. Participation in kinesiology activities compensates for changes in behavior that almost always happen after the occurrence of disability (Nagi \& Hadley, 1972). Adequate physical activity primarily provides amputees with a psychomotor therapy form, after which it provides them with the recreational aspect of quality ways of adapting to the newly formed conditions of life and therefore spending their leisure time which is dominant in healthy individuals (Van de Meent, Hopman \& Frölke, 2013).

When it comes to diving, it can be said that it is becoming an increasingly popular sport for people with disabilities. Water proved to be the best natural medium for the rehabilitation of seriously ill and disabled people. In the last years of the past century, the application of technical developments in the Western world, diving has been increasingly introduced as a special and an attractive way of rehabilitation. Diving is almost an ideal sport for all people with physical disabilities because it connects adventure and experiencing nature with moderate physical effort and training. From the late 1970s to the late 1980s, a number of projects in which people with disabilities have been trained as divers have been reported (Fleming \& Melamed, 1977; Sturgess \& Clatworthy, 1981; Williamson, McDonald, Galligan, Baker \& Hammond, 1984) thus certainly confirming the fact that everyone can dive, regardless of age and physical disabilities. Williamson et al., suggest that diving has the potential to improve selfconcept of people with disabilities. Kovacs and Walter (2015) also proved that individuals benefited from courses that utilize scuba diving skills and techniques. All of the above give the right to examine the impact of diving on the quality of life of amputees, that is, to determine whether programmed diving classes will lead to improvement in the quality of life of people with amputations.

This paper investigates the effects of transformation processes of programmed scuba diving courses on the population of people with disabilities and the success in mastering the elements of scuba diving, as well as the determination of the psychosocial characteristics of people with disabilities and the possibility of their psychosocial status transformation to fully understand the influences of scuba diving programmed classes on people with amputations. In order to achieve the set goal, the sub-criteria are as follow:

1. Determination of transformational processes of the adoption of elements of scuba diving technique.

2. Determining the transformational processes of the psychosocial status of persons with amputations, which implies an assessment of self-esteem, perceived social support, body image, anxiety and depression.

3. Determination of the connection of scuba diving and psychosocial status of persons with disabilities.

H1: A statistically significant difference in the transformational processes persons with disabilities is expected in the sample of the respondents in assessing the acceptance of diving elements.

H2: A statistically significant difference in the transformational processes in assessing the psychosocial status of persons with disabilities is expected.

H3: A statistically significant link between diving and psychosocial status is expected in persons with disabilities after three-week programmed diving courses.

\section{METHOD}

\section{Participants}

The survey covered a sample of 12 Bosnian male examinees who were the veterans of the war in Bosnia and Herzegovina during the years 1992 and 1995. The average chronological age of volunteering examinees was $33,41 \pm 7,01$ years. In regards to the type of injury, $16.7 \%$ of examinees had a lower leg amputation, $25 \%$ had a foot amputation, $50 \%$ a leg amputation, while one respondent had tendon sheath stenosis (Table 1). The basic condition for participating in the study was that the participant could swim, but had no previous experience with diving. 
Table 1. Percentage of disability

\begin{tabular}{ccccccc}
\hline \multicolumn{7}{c}{ Participant percentage of disability } \\
\hline 40 & 50 & 60 & 70 & 80 & 90 & 100 \\
$\mathrm{f} \%$ & $\mathrm{f} \%$ & $\mathrm{f} \%$ & $\mathrm{f} \%$ & $\mathrm{f} \%$ & $\mathrm{f} \%$ & $\mathrm{f} \%$ \\
$\mathbf{1} 8.3$ & $\mathbf{1} 8.3$ & $\mathbf{3} 25.0$ & $\mathbf{1 8} 8.3$ & $\mathbf{2} 16.7$ & $\mathbf{1} 8.3$ & $\mathbf{3 2} 25.0$ \\
\hline
\end{tabular}

Scuba diving program: The total sample of 12 subjects was divided into four groups. The first and second group of examinees came on Mondays and Wednesdays, while the remaining groups, third and fourth, came on Tuesdays and Thursdays in the evening. The total duration of trainings for each specified day was two hours, each group of examinees coming in a span of two hours, which included two sessions per week, for a total of six sessions and a total duration of 12 hours. The sessions were conducted in a pool which was solely used for the participants during training. Research consisted of examinees with no previous experience with diving, but had to have swimming abilities of movement and floating on the water.

The study was conducted by a professor of physical education and sport who is also a recreational diving instructor licensed by the Certified Diving Association (SDI and SSI). The licensed instructor gave an introductory lecture before the programmed diving classes in which the examinees were familiarized with the basic elements of the theory of diving, such as physics and diving, the anatomy of the human body and diving, diving incidents prevention and their consequences on the human body, and elements of performing techniques in diving.

Measurement of the adoption of diving elements was performed by assessing the respondents for each intended technical scuba diving element with the diving apparatus. The scale for assessing the acceptance of scuba diving elements with the diving apparatus contains 20 exercises, and each performance is evaluated on a scale of 5 degrees. The total score ranges from 20-100. The assessment criterion was established in accordance with the standards for performing diving technique, diving association SSI (Scuba School International) and scaling from 1 to 5, thus forming a grading criterion as follows: Score 1: not adopted the technical element of diving with diving apparatus, Score 2: poorly adopted the technical element of diving with diving apparatus, Score 3: partially adopted the technical element of diving with diving apparatus, Score 4: adopted the technical element of diving with the diving apparatus, Score 5: fully adopted the technical element of diving with diving apparatus.

Adoption of diving was realized in such a way that each diving element with and without diving equipment was individualized with the possibility of exercise repetition, i.e. if the examinee believes that he may perform the exercise better in the next than in the previous attempt. Before entering the pool, examinees were familiarized with elements of performing techniques in diving. Underwater exercises were performed in such a way that the instructor first demonstrated each exercise after which the examinee would repeat the same exercise with or without the diving instructor's assistance, depending on how well he was able to surpass the movement handicap in an aqueous environment.

Psychosocial status evaluation: Assessment of the psychosocial status of the respondents were carried out in the initial phase of the measurement before scuba diving performance and the final phase measurement after the completion of scuba diving program in the pool to be able to compare and contrast the findings of both procedures. In order to collect the date, five different scales were used as the collection tools. The mentioned scales are the Rosenberg Self-Esteem Scale (Rosenberg, 1965), Multidimensional Scale of Perception of Social Support (Zimet, Dahlem, Zimet \& Farley, 1988), Handicap Body-Image Scale (Breakey, 1997), Zung Self-Rating Anxiety Scale (Zung, 1971) and Zung Self-Rating Depression Scale (Zung, 1965).

Self-esteem in this study is assessed using the Rosenberg Self-Esteem Scale which contains 10 statements corresponding to the Likert type with four degrees, 1 to 4 . The total score is formed as a linear combination of estimates on each of the statements. The higher score marks mean more selfesteem, and the results range from 10 to 40 points.

Multidimensional Scale Perceived Social Support scale consists of 12 questions which the examinee may answer by circling one of several provided answers scored by a seven-degree scale as in 1- completely disagree, 2- strongly disagree, 3- disagree, 4- no attitude towards, 5- agree, 6- strongly agree, 7- completely agree. Questions are set up in a way so that a higher score means a higher level of Perceived Social Support by the examinee. 
The body image is examined by using the Handicap Body-Image Scale which consists of 20 questions scored on a scale from 1 to 5 (never, rarely, sometimes, often, and always). Lower results indicate the absence of body image problems, and higher results indicate problems with the experience of one's own body in people with disabilities. Three of the questions, number 3, 12 and 16 are reversed for reliability.

Self-Rating Anxiety Scale contains 20 statements which aim to measure the anxiety levels of the respondents in different cognitive and psychological states. The respondent, with the Self-Rating Anxiety scale, estimates his disturbances in the last seven days on a four-step scale, never, rarely, sometimes, often, mostly or always. It has been interpreted that the result of 50-59 points represents a weak to moderate anxiety, 60-69 represents moderate anxiety, and 70 and more points a strong anxiety.

The Self Rating Depression Scale, the basic characteristics of depression were made: affective (depressed mood, sadness, plausibility), physiological (night or premature morning awakening, tachycardia and tachyarrhythmias, decreased appetite), psychomotor (temporal and spatial slow motion, restlessness, cramps in certain groups of musculatures) and psychological disturbances (indecision, confusion, dissatisfaction with achieved results, suicidal thinking). The scale contains a 20 -item measure of the symptoms of depression, and for each statement, a response to a four-degree scale is given: never or rarely ( 1 point), sometimes ( 2 points), often ( 3 points), mostly or always ( 4 points). The total score is converted to a scale of 25 to 100 .

\section{Statistical analysis}

The basic statistical parameters, measures of central tendency, measures of dispersion, as well as frequency and percentages were calculated based on the data collection tools. The Wilcoxon test for matched pairs and the t-test for dependent samples were used. To determine the correlation between diving and psychosocial status, Spearman's correlation coefficient was implemented. In order to assess the symmetry of the distribution of results, a Kolmogorov-Smirnov test was used based on the comparison of empirical and theoretical distribution. For determining the significant differences between the initial and final measurements in relation to the quality of life, the t-test for dependent sample was used. Research data was analyzed in the statistical package SPSS 20 for Windows. In all comparisons, statistical significance level was accepted as $\mathrm{p}<0.05$.

\section{RESULTS}

Results are attained based on the collected data after the transformation process of three-week programmed diving program.

Table 2. Measures of central tendency and measures of dispersion, Kolmogorov-Smirnov test

\begin{tabular}{lcccccccc}
\hline Variable & AS & SD & VAR & MIN & MAX & SKEW & KURT & KS \\
\hline SDT & 50.04 & 31.65 & 1001.78 & 20.00 & 97.00 & 0.18 & -1.90 & 0.00 \\
SE & 24.79 & 2.20 & 4.86 & 20.00 & 28.00 & -0.58 & -0.15 & 0.01 \\
MSPSS & 76.54 & 6.39 & 40.86 & 64.00 & 84.00 & -0.28 & -1.09 & 0.07 \\
BI & 42.16 & 8.64 & 74.66 & 30.00 & 59.00 & 0.74 & -0.41 & 0.20 \\
ANX & 44.37 & 4.75 & 22.59 & 37.00 & 57.00 & 0.87 & 1.36 & 0.016 \\
DEP & 57.83 & 4.269 & 18.23 & 44.00 & 62.00 & -1.64 & 3.37 & 0.00 \\
\hline
\end{tabular}

Table 2 shows the measures of central tendency and measures of dispersion based on the Kolmogorov-Smirnov test (KS). The results indicate that the variables, (SDT) scuba diving technique, (SE) self-esteem, (ANX) anxiety, and (DEP) depression did not satisfy the symmetric distribution of results (KS=0.00, $0.01,0.016$ and 0.00 respectively). These will be used to test the hypothesis of these variables using the Wilcoxon equivalence test. The remaining two (MSPSS) multidimensional scale perceived social support and (BI) body image variables, with $\mathrm{KS}=0.07$ and 0.20 respectively, satisfy the symmetric distribution of results, and the t-test for the dependent sample will be used to check hypotheses.

Table 3. Wilcoxon test for scuba diving technique

\begin{tabular}{lccc}
\hline SDT & $\mathbf{N}$ & $\mathbf{Z}$ & $\mathbf{p}$ \\
\hline Initial-Final & 12 & $-3,06$ & 0,01 \\
\hline
\end{tabular}


The results of the Wilcoxon test based on the variable (SDT) scuba diving technique is shown in Table 3. The initial and final measurements for the variable of diving technique displayed a statistically significant difference given that the $Z=-3.06$ index is significant at the level of $(p \leq 0.01)$.

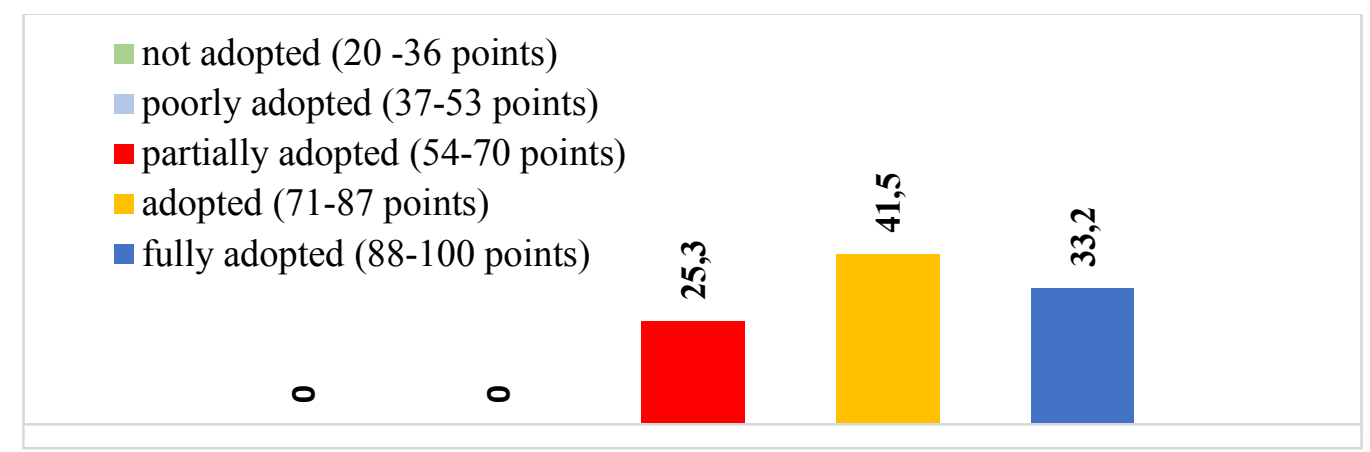

Figure 1. Measurement of the adoption of scuba diving elements

The distribution of data after the transformation process has changed and is in favor of the final measurement that shows that $25.3 \%$ of the respondents partially adopted the scuba diving elements, $41.5 \%$ of the participants adopted the scuba diving elements and $33.2 \%$ of them completely adopted the elements of diving technique.

Table 4. T-test results for the multidimensional scale perceived social support

\begin{tabular}{lccccc}
\hline MSPSS & N & AS & SD & t & p \\
\hline Initial & 12 & 74,66 & 7,30 & & \\
Final & 12 & 78,41 & 4,94 & $-3,23$ & $\mathbf{0 , 0 1}$ \\
\hline
\end{tabular}

Table 4 displays the t-test results for the (MSPSS) multidimensional scale perceived social support. Through the t-test, it can be seen that the arithmetic mean of the initial measurement was $74.66 \pm 7.30$, while in the final measuring, it was higher at $78.41 \pm 4.94$. Significant difference was found between initial and final measurements regarding perceived social support $(\mathrm{t}=-3.23, \mathrm{p} \leq 0.01)$.

Table 5. Initial and final measurements for the variable of anxiety

\begin{tabular}{lccc}
\hline $\boldsymbol{A N X}$ & $\mathbf{N}$ & $\mathbf{Z}$ & $\mathbf{p}$ \\
\hline Initial-Final & 12 & $-1,93$ & 0,05 \\
\hline
\end{tabular}

Initial and final measurements for the variable of (ANX) anxiety are displayed in table 5 . It can be seen that there is a statistically significant difference between the initial and final measurements of the variable of anxiety $(\mathrm{Z}=-1.93, \mathrm{p} \leq 0.05)$.

Table 6. Correlation analysis

\begin{tabular}{lcccccc}
\hline VAR & SDT & SE & MSPSS & BI & ANX & DEP \\
\hline SDT & 1 & 0.52 & $.75^{* *}$ & -0.49 & -0.22 & 0.47 \\
SE & 0.52 & 1 & 0.35 & -0.3 & 0.24 & 0.12 \\
MSPSS & $0.75^{* *}$ & 0.35 & 1 & $-.65^{*}$ & -0.02 & 0.18 \\
BI & -0.49 & -0.3 & $-0.65^{*}$ & 1 & -0.41 & -0.5 \\
ANX & -0.22 & 0.24 & -0.02 & -0.41 & 1 & 0.4 \\
DEP & 0.47 & 0.12 & 0.18 & -0.5 & 0.4 & 1 \\
\hline
\end{tabular}

** Correlation $0.01,{ }^{*}$ Correlation 0.05

Table 6 shows the results of Spirman's coefficient of correlation after a three-week programmed scuba diving training. Based on the correlation results in the final measurement, it was found that (STD) scuba diving technique variable is in positive correlations with the (MSPSS) multidimensional scale perceived social support $(\mathrm{r}=0.75)$ variable at the level of statistical significance $(\mathrm{p} \leq 0.01)$. The multidimensional scale perceived social support variable is in a positive correlation with scuba diving technique variable $(\mathrm{r}=0.75)$ at the level of statistical significance $(\mathrm{p} \leq 0.01)$ and is negatively correlated $(\mathrm{r}=-0.65)$ with the $(\mathrm{BI})$ body image variable at the level of statistical significance $(\mathrm{p} \leq 0.05)$. 


\section{DISCUSSION}

There is a large number of studies related to scuba diving with a healthy population. Majority of these studies are related to scuba diving medicine (Bosco, Rizzato, Moon \& Camporesi, 2018), safety aspects of scuba diving, rules and procedures in scuba diving activities (Lucrezi, Egi, Pieri, Burman, Ozyigit, et al., 2018), technological development of scuba diving equipment (Harvey, Pollock, Gant, Hart, Mesley, \& Mitchell, 2016) accidents prevention (Gempp, Lyard \& Louge, 2017), medical treatments of scuba diving diseases (Papadopoulou, Germonpré, Cosgrove, Eckersley, Dayton, et al., 2018). as well as the performance of diving activities itself such as professional and recreational diving, underwater work and research. In the available scientific databases, the number of studies regarding scuba diving and people with disabilities are limited in the numbers of scientific publication. Reasons for this most surely lies in the fact that interest in research related to scuba diving and people with disabilities began to rise only at the turn of this century, that is with the development of scuba diving medicine such as hyperbaric medicine and scuba diving safety rules. One of the reasons for this is that, this type of research must be based on an interdisciplinary approach within various scientific fields. There is the impossibility of generalization of results due to the use of small samples and large variety in the types and degree of disability, physical and psychological characteristics of examinees.

Authors Cheng and Diamond (2005) point out that scuba diving can be a pleasurable experience that potentially affects how individuals see themselves, but also affects their quality of life as confirmed by the results of this research. Cheng and Diamond, also conducted a study highlighting that scuba diving can potentially help to improve self-esteem and quality of life the findings of the study showed that participants had a positive attitude when initial and final measurements were compared in terms of their self-esteem and depression levels. After the three-week scuba diving program, amputees had higher self-esteem and their level of depression had significantly lessened. These results are also supported by the following research by Williamson et al (1984). This research examined the impact of standard diving courses on sixteen people with disabilities. The study included people with head injuries, paraplegia and amputations, and their study supports the hypothesis that diving can improve mental and physical state of persons with disabilities. In addition, Carin-Levy and Jones (2007) highlighted a number of psychosocial benefits of diving among people with disabilities. Among other things, he states that one of the big advantages of diving with people with disabilities causes improvement in the quality of life, as also confirmed by the results of this research. Combining the findings of anxiety and depression variables, it is clearly seen that there has been an improvement in the quality of the participants' lives.

In terms of the variable of scuba diving technique, the following research has also been supported by the current study findings. As mentioned in Cheng and Diamond (2005), the scuba diving association for handicapped individuals created different diving categories for people with disabilities to allow them to scuba dive independently or with assistance of diving buddy or instructor. This proves that people with disabilities can and are able to acquire the techniques necessary for scuba diving and they are able to apply these under water. According to the results of the current study in hand, after the three-week programmed scuba diving training, a statistically significant difference between initial and final measurements have been found, at significant level of $(p \leq 0.01)$. These results indicate that different categories in body disabilities do not create many differences and limitations under water, whereas these limitations are present on hard surface. Individuals with disabilities can perform scuba diving effectively and the participants of this study have been able to complete the provided training and accomplish the objectives of the scuba diving course.

The relationship between anxiety and scuba diving performance in this research achieved results in the final measurement at the level of statistical significance of $(\mathrm{p} \leq 0.05)$. This indicates that participants experienced anxiety ranging from moderate to severe. These results have been related to the complexity of scuba diving maneuvers which was conditioned by the type of the disability (Griffiths, Steel \& Vaccaro, 1979). Individuals with more severe disabilities showed anxiety depending on the difficulty level of the scuba diving maneuvers. For simple moves and maneuvers, all participants acquired the taught concepts and were able to apply them without their anxiety levels increasing. However, it was discovered that more complex moves and techniques proved to be more challenging for certain participants. These were the respondents with more significant disabilities such as losing a limb completely and they had more anxiety completing these higher-level moves. 
Perceived Social Support defined as the support from family, friends, media and community CarinLevy and Jones (2007), at the level of statistical significance of ( $\mathrm{p} \leq 0.01)$, displayed an improvement in the final measurement. This illustrates that participants during the scuba diving program received significant social support from family, friends, media and community. Participants indicated that they received social support to motivate them continue scuba diving. It is important to note that participants pointed out the fact that major support has come from the scuba diving community which consists of divers without disabilities. According to the correlation analysis results, it was shown that perceived social support has a positive correlation with the variable scuba diving technique. This specifies that social support has a constructive effect on learning the scuba diving rechniques. As the participants believed that they were receiving support from others, they were able to perform better and acquire the necessary skills to scuba dive sucessfully.

This study indicates the importance of creating more opportunities for disabled people to be introduced with scuba diving in order to provide them with the positive influences shown in this research. The statistically significant differences found on the variables of learning scuba diving techniques, self-esteem, depression and anxiety inform that individuals with disabilities can notably benefit from scuba diving. The possible limitations of this duty consist of the small number of the participants. The size of the sample group is recommended to be enlarged so that the research findings can be generalized. In addition, participants with different severity of disabilities along with a wide variety of disabilities can be researched to observe if these would lead to different results (Patkiewicz, 2015).

\section{CONCLUSION}

Consequently, based on the obtained results, it can be concluded that after a three-week programmed diving classes, the social support of people with disabilities has improved. Also, on the basis of research results, it can be generally concluded that people with disabilities adopted elements of scuba diving technique. This data supports the fact that people without disabilities, after diving training and education, adopt elements of diving technique and they are qualified for recreational scuba diving under supervision of a diving instructor or as an independent scuba diver depending on which category scuba divers belong to with or without supervision. This clearly shows that people with disabilities are as well qualified for recreational diving as people with no disabilities, which again suggests that disability in and under water does not represent a barrier for recreational underwater activities.

\section{PRACTICAL APPLICATION}

Multidisciplinary approach in this study discovers the principles of complementarity that facilitate easier access to different areas of education, treatment, and rehabilitation of people with disabilities. These results can be supported by the fact that more studies are to be involved and develop the knowledge of these specific areas. Even though we take into account the fact that Europe and the world promote sports for people with disabilities, the results can serve as a reflection on the launch of specific studies in the field of diving people with amputations. It is also worth mentioning that people with disabilities can perform as effectively as divers without any disabilities. Even though having a special association or different categories can be helpful depending on the severity of the person's disability and motivate people with disabilities to scuba dive, the results of this research show that there is no such need for a separate entity as disabled individuals are able to achieve the same results as people with no disabilities. In addition, this research can be the starting point for future complex research with different severity of disabilities along with a wide variety of disabilities to deal with this issue, which could shed more light to the topic of disabled people scuba diving.

\section{REFERENCES}

Bosco, G., Rizzato, A., Moon, R. E., \& Camporesi, E. M. (2018). Environmental Physiology and Diving Medicine. Frontiers in Psychology, 9. https://doi.org/10.3389/fpsyg.2018.00072

Breakey, J. W. (1997). Body image: the lower-limb amputee. JPO: Journal of Prosthetics and Orthotics, $9(2), 58-66$.

Buning, M. E., \& Schmeler, M. R. (1999). Effects of the Transition to Powered Mobility on Occupational Performance, 20. 
Cantor, N. L. (1972). A Patient's Decision to Decline Life-Saving Medical Treatment: Bodily Integrity versus the Preservation of Life. Rutgers Law Review, 26, 228.

Carin-Levy, G., \& Jones, D. (2007). Psychosocial Aspects of Scuba Diving for People with Physical Disabilities: An Occupational Science Perspective. Canadian Journal of Occupational Therapy, 74(1), 6-14. https://doi.org/10.2182/cjot.06.07.

Cheng, J., \& Diamond, M. (2005). SCUBA Diving for Individuals with Disabilities. American Journal of Physical Medicine \& Rehabilitation, $84 \quad$ (5), 369. https://doi.org/10.1097/01.PHM.0000159974.01251.E2.

Compton, D. M., Eisenman, P. A., \& Henderson, H. L. (1989). Exercise and Fitness for Persons with Disabilities. Sports Medicine, 7(3), 150-162. https://doi.org/10.2165/00007256-198907030-00002

Fleming, N., \& Melemed, Y. (1977). Report of a scuba diving training course for paraplegics and double leg amputees with an assessment of physiological and rehabilitation factors. SPUMS Journal of the South Pacific Underwater Medicine Society.MS, 7(1), 1. http://archive.rubiconfoundation.org/xmlui/handle/123456789/6132? show=full.

Gallagher, P., \& MacLachlan, M. (2004). The Trinity amputation and prosthesis experience scales and quality of life in people with lower-limb amputation 11 No commercial party having a direct financial interest in the results of the research supporting this article has or will confer a benefit on the author(s) or on any organization with which the author(s) is/are associated. Archives of Physical Medicine and Rehabilitation, 85(5), 730-736. https://doi.org/10.1016/j.apmr.2003.07.009

Gempp, E., Lyard, M., \& Louge, P. (2017). Reliability of right-to-left shunt screening in the prevention of scuba diving related-decompression sickness. International Journal of Cardiology, 248, 155158. https://doi.org/10.1016/j.ijcard.2017.08.059

Griffiths, T. J., Steel, D. H., \& Vaccaro, P. (1979). Relationship between Anxiety and Performance in Scuba Diving. Perceptual and Motor Skills, 48(3), 1009-1010. https://doi.org/10.2466/pms.1979.48.3.1009

Guttmann, M. (1976). The link between equilibrium segregation and precipitation in ternary solutions exhibiting temper embrittlement. Metal Science, 10(10), 337-341. https://doi.org/10.1179/030634576790431390

Harvey, D., Pollock, N. W., Gant, N., Hart, J., Mesley, P., \& Mitchell, S. J. (2016). The duration of two carbon dioxide absorbents in a closed-circuit rebreather diving system, 46(2), 6.

Kovacs, C. R., \& Walter, D. (2015). Scuba Diving and Kinesiology: Development of an Academic Program. Journal of Physical Education, Recreation \& Dance, 86(3), 12-17. https://doi.org/10.1080/07303084.2014.998394.

Laferrier, J. Z., Teodorski, E., \& Cooper, R. A. (2015). Investigation of the Impact of Sports, Exercise, and Recreation Participation on Psychosocial Outcomes in a Population of Veterans with Disabilities: A Cross-sectional Study. American Journal of Physical Medicine \& Rehabilitation, 94(12), 1026. https://doi.org/10.1097/PHM.0000000000000263.

Levy, A. R., Polman, R. C. J., Clough, P. J., Marchant, D. C., \& Earle, K. (2006). Mental Toughness as a Determinant of Beliefs, Pain, and Adherence in Sport Injury Rehabilitation. Journal of Sport Rehabilitation, 15(3), 245-254. https://doi.org/10.1123/jsr.15.3.245

Lucrezi, S., Egi, S. M., Pieri, M., Burman, F., Ozyigit, T., Cialoni, D., Saayman, M. (2018). Safety Priorities and Underestimations in Recreational Scuba Diving Operations: A European Study Supporting the Implementation of New Risk Management Programmes. Frontiers in Psychology, 9. https://doi.org/10.3389/fpsyg.2018.00383

Nagi, S. Z., \& Hadley, L. W. (1972). Disability Behavior: Income Change and Motivation to Work. ILR Review, 25(2), 223-233. https://doi.org/10.1177/001979397202500206

Noreau, L., \& Shephard, R. J. (1995). Spinal Cord Injury, Exercise and Quality of Life. Sports Medicine, 20(4), 226-250. https://doi.org/10.2165/00007256-199520040-00003

Papadopoulou, V., Germonpré, P., Cosgrove, D., Eckersley, R. J., Dayton, P. A., Obeid, G., Balestra, C. (2018). Variability in circulating gas emboli after a same scuba diving exposure. European Journal of Applied Physiology, 118(6), 1255-1264. https://doi.org/10.1007/s00421-018-3854-7 
Patkiewicz, J. (2015). The specificity of diving of the disabled. Physiotherapy, 23(3), 34-39. https://doi.org/10.1515/physio-2015-0017

Rosenberg, M. (1965). Rosenberg self-esteem scale (RSE). Acceptance and Commitment Therapy. Measures Package, 61, 52.

Seymour, R. (2002). Prosthetics and Orthotics: Lower Limb and Spinal. Lippincott Williams \& Wilkins.

Shontz, F. C. (1974). Body Image and its Disorders. The International Journal of Psychiatry in Medicine, 5(4), 461-472. https://doi.org/10.2190/RK8P-RR62-UV6W-B31L

Sturgess, C. E. N., \& Clatworthy, M. C. (1981). A scuba diving acquaintance course for the severely disabled. South Pacific Underwater Medicine Society Journal, 11, 27-31.

Van de Meent, H., Hopman, M. T., \& Frölke, J. P. (2013). Walking Ability and Quality of Life in Subjects with Transfemoral Amputation: A Comparison of Osseointegration With Socket Prostheses. Archives of Physical Medicine and Rehabilitation, 94(11), 2174-2178. https://doi.org/10.1016/j.apmr.2013.05.020

Williamson, J. A., McDonald, F. W., Galligan, E. A., Baker, P. G., \& Hammond, C. T. (1984). Selection and training of disabled persons for scuba-diving. Medical and psychological aspects. The Medical Journal of Australia, 141(7), 414-418.

Zidarov, D., Swaine, B., \& Gauthier-Gagnon, C. (2009). Quality of Life of Persons with Lower-Limb Amputation During Rehabilitation and at 3-Month Follow-Up. Archives of Physical Medicine and Rehabilitation, 90(4), 634-645. https://doi.org/10.1016/j.apmr.2008.11.003

Zimet, G. D., Dahlem, N. W., Zimet, S. G., \& Farley, G. K. (1988). The multidimensional scale of perceived social support. Journal of Personality Assessment, 52(1), 30-41.

Zung, William W. (1971). A rating instrument for anxiety disorders. Psychosomatics: Journal of Consultation and Liaison Psychiatry.

Zung, William WK. (1965). A self-rating depression scale. Archives of General Psychiatry, 12(1), 6370 .

CITATION OF THIS ARTICLE

Aganović, Z. (2019) Effects of Scuba Diving Program on Bosnian War Veterans with Amputations. International Journal of Sport Exercise \& Training Sciences, 5 (1), 6-14. doi:10.18826/useeabd.506032 